\title{
ASOSIASI FUNGI MIKORIZA ARBUSKULA PADA TANAMAN MANGROVE DI DESA PASIR KECAMATAN MEMPAWAH HILIR KABUPATEN MEMPAWAH
}

\author{
(Association of Arbuscular Mychorrhizal Fungi on Mangrove Plants in Pasir Village \\ Mempawah Regency)
}

\author{
Fety Fitri Ramadhani, Hanna Artuti Ekamawanti, Sofwan Anwari \\ Fakultas Kehutanan Universitas Tanjungpura, Jalan Imam Bonjol Pontianak 78124 \\ Email : fitrifety39@gmail.com
}

\begin{abstract}
This research was aimed at discovering the types of Arbuscular Mycorrhizal Fungi (AMF) associated with mangrove plants. The research was conducted in Pasir Village, Mempawah Hilir District, Mempawah Regency, and the Silvicultural Laboratory of Forestry Faculty, Tanjungpura University Pontianak for one month. The samples collection of soil and root done survey method used purposive sampling technique. The primary data were the number of spores, genus of $A M F$, and $A M F$ infection on root samples. While the secondary data were $p H$, air temperature, soil temperature, humidity, diameter, and height. The results showed that there were 7 species of Glomus spp. and mangrove plant (Avicennia marina, Bruguiera cylindra, Rhizophora stylosa) with AMF spore density of 247 spores $/ 100 \mathrm{gr}$ soil and level of root infection percentage from low class (class 2) up to medium class (class 3).
\end{abstract}

Keywords: arbuscular mycorrhizal fungi (AMF), association, mangroves.

\section{PENDAHULUAN}

Mikoriza adalah suatu bentuk hubungan simbiosis mutualisme antara cendawan atau fungi (myces) dengan perakaran (rhiza) tumbuhan tinggi. FMA juga mempunyai selang ekologis dan dapat dijumpai dalam habitat hutan tropis, daerah temperate, semak, sabana daerah arid, semi arid, hutan hujan tropika, dan padang rumput. Selang ekologi FMA juga dijumpai pada habitat berair seperti tanah sawah, hutan mangrove dan lain-lain (Setiadi 1989). FMA tergolong ke dalam endomikoriza, membentuk organ-organ khusus dan mempunyai perakaran yang spesifik yaitu arbuskul, vesikula, dan spora. Tanaman yang bermikoriza tumbuh lebih baik dari tanaman tanpa mikoriza dikarenakan mikoriza secara efektif dapat meningkatkan tanah umtuk mendapatkan zat yang dibutuhkan seperti FMA.

Mangrove adalah tanaman berkayu yang tumbuh antara darat dan laut di lintang tropis dan sub-tropis, tanaman ini berasosiasi dengan mikroba, jamur, tanaman dan hewan (Kathiresan dan Bingham 2001). Suplai oksigen ke akar penting bagi pertumbuhan dan penyerapan nutrient karena tanah anaerob, maka beberapa tumbuhan mangrove membentuk strainer pneumatofora (akar lapis). Mekanisme yang dimungkinkan terjadi yaitu asosiasi tumbuhan mangrove dengan 
mikrob tanah untuk mendapatkan zat yang dibutuhkan seperti FMA. Kalimantan Barat mempunyai kawasan hutan mangrove terluas ke-5 di Indonesia sekitar 213.000 ha (Noor dkk. 2006). Luasan kawasan hutan mangrove di Mempawah Hilir sekitar 16.042,2 ha (Khairuddin 2014). Kondisi hutan mangrove di Desa Pasir Kecamatan Mempawah Hilir Kabupaten Mempawah mengalami kerusakan cukup parah bahkan sampai terjadi abrasi. Upaya yang dilakukan untuk mengatasi kerusakkan hutan mangrove yaitu dengan melakukan kegiatan rehabilitasi. Keberhasilan penanaman kembali hutan mangrove di Desa Pasir Kecamatan Mempawah Hilir Kabupaten Mempawah membutuhkan teknologi yang tepat. Salah satu teknologi yang banyak dikerjakan dalam penanaman kembali tanaman hutan yaitu pemanfaatan fungi mikoriza arbuskula (Rini dkk. 2015). Pemanfaatan FMA dapat meningkatkan pertumbuhan tanaman pada tingkat kesuburan tanah yang rendah, lahan terdegradasi dan membantu memperluas fungsi sistem perakaran dalam memperoleh nutrisi (Galii dkk. 1993). Hasil penelitian Delvian (2003) menunjukkan penyebaran yang paling dominan dimana 25 spesies dari 37 spesies yang ditemukan adalah fungi mikoriza tipe Glomus sp. mampu hidup dan berkembang pada kondisi salinitas yang tinggi.

Gustian dkk. (2015) menyatakan adanya asosiasi antara FMA dengan tegakan Avicennia spp. penelitian lain menemukan 4 pohon di hutan mangrove meliputi Rhizophora mucronata, $R$. stylosa, Sonneratia sp., Avicennia marina yang diamati berasosiasi dengan mikoriza (Aboe dkk. 2007). Kajian tentang asosiasi FMA pada tumbuhan mangrove sebagai dasar pemanfaatan FMA pada penanaman kembali tumbuhan mangrove masih sangat sedikit, oleh karena itu perlu dilakukan penelitian tentang asosiasi FMA pada tumbuhan mangrove di Desa Pasir Kecamatan Mempawah Hilir Kabupaten Mempawah. Tujuan penelitian adalah untuk mendapatkan informasi keberadaan jenis FMA yang berasosiasi dengan jenis-jenis FMA pada tanaman mangrove (A. marina, B. cylindrica, $R$. stylosa) berdasarkan tipe-tipe spora FMA dan persentase infeksinya dalam akar tanaman mangrove.

\section{METODE PENELITIAN}

\section{Waktu dan Tempat Penelitian}

Penelitian dilaksanakan di Desa Pasir Kecamatan Mempawah Hilir Kabupaten Mempawah dan Labotorium Silvikultur Fakultas Kehutanan Universitas Tanjungpura Pontianak selama 1 bulan.

\section{Prosedur Penelitian}

Proses pengambilan sampel akar dan tanah rizosper dilapangan dilakukan menggunakan metode Purposive Sampling dengan mengambil 3 (tiga) titik pengambilan di sekitar perakaran (rhizospher) dari tanaman mangrove ( $A$. marina, $B$. cylindrica, $R$. stylosa) dengan 3 kali ulangan dari setiap jenis tanaman yang telah ditentukan kemudian dikompositkan menjadi 100 
gram tanah setiap tegakan sehingga keseluruhan sampel berjumlah 9 sampel tanah dan 9 sampel akar. Pada waktu pengambilan sampel dilakukan pengukuran suhu tanah dan udara, kelembapan udara, dan $\mathrm{pH}$ tanah. Pengukuran salinitas dan tesktur tanah dibawa ke Laboratorium Kimia dan Kesuburan Tanah. Data yang dikumpulkan dari proses pengamatan FMA berupa jumlah spora/100 g tanah mangrove dan genus FMA serta persen infeksi dalam akar. Pengamatan spora dilakukan dengan teknik saring basah (Brundrett dkk. 1996) dan identifikasi dilakukan sampai tingkat genus dengan memperhatikan bentuk, warna, lekatan tangkai hifa dan tekstur permukaan spora. Sedangkan proses infeksi pada akar dalam penelitian ini dilakukan dengan metode sistematik yaitu metode slide (Setiadi 1992). Persen infeksi ditentukan berdasarkan perbandingan akar yang terinfeksi dengan jumlah seluruh potongan akar yang diamati. Persentase akar terinfeksi dihitung dengan rumus :

$\%$ Infeksi= $\frac{\text { Jumlah overview contoh akar yang terinfeksi }}{\text { Jumlah overview seluruh akar yang diamati }} \times 100 \%$

Tingkat infeksi ditentukan melalui The Institute of Mycorrizal Research and Development, USDA Forest Service, Athena, Georgia (Setiadi, 1992) yang terdiri dari 5 kelas yaitu:

1. Kelas 1 , bila infeksinya $0 \%-5 \%$, sangat rendah.

2. Kelas 2,bila infeksinya $6 \%-25 \%$, rendah.

3. Kelas 3, bila infeksinya $26 \%-50 \%$, sedang.

4. Kelas 4 , bila infeksinya $51 \%-75 \%$, tinggi.

5. Kelas 5, bila infeksinya $76 \%$ $100 \%$, sangat tinggi.

\section{HASIL DAN PEMBAHASAN}

\section{Kepadatan FMA pada tanaman mangrove}

Tabel 1. Jumlah Kepadatan Spora FMA /100 gr pada Rizosfer Tanaman Mangrove $(A$. marina, B. cylindrica, R. stylosa) (The Amount of AMF Spore Density /100 gr of Mangrove Rhizosphere (A. marina, B. cylindrica, R. stylosa).

\begin{tabular}{cccc}
\hline & \multicolumn{3}{c}{ Jumlah spora per 100 gr tanah } \\
\cline { 2 - 4 } Tipe Spora & Avicennia marina & Bruguiera cylindrica & Rhizosphora stylosa \\
\hline Glomus sp. 1 & 4,6 & 6 & 7 \\
Glomus sp. 2 & 18,6 & 16 & 18 \\
Glomus sp. 3 & 20,6 & 16 & 13,6 \\
Glomus sp. 4 & 12,3 & 11,3 & 13,3 \\
Glomus sp. 5 & 15,3 & 11 & 16 \\
Glomus sp. 6 & 11 & 12,6 & 11,3 \\
Glomus sp. 7 & 4,3 & 3 & 7,3 \\
\hline jumlah spora & 87 & 76 & 86 \\
\hline \multicolumn{2}{c}{ Pengamatan dan identifikasi spora } & Kecamatan Mempawah Hilir Kabupaten \\
FMA dari 9 sampel pada rhizosfer akar & Mempawah ditemukan kepadatan spora \\
tanaman mangrove (A. marina, B. & FMA tertinggi adalah jenis Glomus sp. \\
cylindrica, R. stylosa) di Desa Pasir & 2 pada rizosfer tanaman A. marina.
\end{tabular}


yang menunjukkan bahwa Glomus sp. 2 mendominasi dibanding dengan jenis FMA lainnya. Glomus sp. 2 juga ditemukan pada tanaman mangrove $B$. cylindrica, $R$. stylosa. Rizosfer $A$. marina dan di rizosfer $R$. stylosa kedua jenis tanaman ini memiliki kelimpahan spora yang tinggi dibandingkan dengan jenis tanaman $B$. cylindrica. Baon (1998) juga mengemukakan tanah mangrove yang bercirikan tanah berlumpur cenderung Glomus spp. yang dominan hidup. Identifikasi spora FMA dapat dilihat dari bentuk spora, warna spora, dinding spora, tangkai hifa dan tesktur permukaan spora berdasarkan buku manual for the identification of VA mycorrhizal fungi (Schenk dan Perez 1990) sebagai acuan untuk karakterisasi spora ditemukan 7 tipe spora FMA yang dapat dilihat pada Tabel 2.

Tabel 2. Karakteristik Tipe Spora FMA pada Tanaman Mangrove (A. marina, B. cylindrica, $R$. stylosa) dengan Perbesaran Mikroskop $400 \quad \mathrm{X}$ (Characteristics of AMF Spores on Mangrove (A. marina, B. cylindrica, $R$. stylosa) by 400x Zooming).

\begin{tabular}{|c|c|c|c|}
\hline No & Tipe Spora & Jenis Karakteristik & Keterangan \\
\hline 1. & Glomus sp.1 & & $\begin{array}{l}\text { Spora berbentuk lonjong, berwarna } \\
\text { kuning keemasan, permukaan halus dan } \\
\text { terdapat perlekatan hifa serta memiliki } \\
\text { dinding sel. }\end{array}$ \\
\hline 2. & Glomus sp. 2 & & $\begin{array}{l}\text { Spora berbentuk lonjong, berwarna } \\
\text { kuning, permukaan halus dan terdapat } \\
\text { perlekatan hifa serta memiliki dinding } \\
\text { sel. }\end{array}$ \\
\hline 3. & Glomus sp. 3 & & $\begin{array}{l}\text { Spora berbentuk lonjong, berwarna } \\
\text { kuning, permukaan halus dan terdapat } \\
\text { perlekatan hifa serta memiliki dinding } \\
\text { sel. }\end{array}$ \\
\hline 4. & Glomus sp. 4 & & $\begin{array}{l}\text { Spora berbentuk bulat, berwarna kuning } \\
\text { keemasan dan tidak terdapat hifa serta } \\
\text { memiliki tekstur yang kasar dan miliki } \\
\text { dinding sel. }\end{array}$ \\
\hline 5. & Glomus sp. 5 & & $\begin{array}{l}\text { Spora berbentuk bulat berwarna kuning, } \\
\text { permukaan halus serta terdapat } \\
\text { perlekatan hifa dan memiliki dinding } \\
\text { sel. }\end{array}$ \\
\hline 6. & Glomus sp. 6 & & $\begin{array}{l}\text { Spora berbentuk bulat berwarna kuning- } \\
\text { kecoklatan, tidak terdapat hifa serta } \\
\text { memiliki permukaan yang kasar. }\end{array}$ \\
\hline 7. & Glomus sp. 7 & & $\begin{array}{l}\text { Spora berbentuk bulat berwarna kuning } \\
\text { kecoklatan, tidak memiliki benang hifa } \\
\text { serta memiliki dinding sel dan } \\
\text { permukaan yang halus. }\end{array}$ \\
\hline
\end{tabular}


Hasil karakteristik yang dilakukan di Laboratorium Silvikultur Fakultas Kehutanan Tanjungpura Pontianak, menunjukkan adanya populasi FMA dan membentuk asosiasi dengan menginfeksi akar-akar tanaman ditemukan 7 tipe spora dari genus Glomus spp. mendominasi rizosfer tanaman mangrove. Delvian (2010) yang mempelajari FMA pada hutan pantai mendapatkan spora FMA tipe Glomus mempunyai frekuensi kehadiran paling tinggi yang diikuti berturut-turut spora tipe Acaulospora, Sclerocystis dan Gigaspora pada hutan pantai pulau Pandang kabupaten Batubara, Sumatera Utara. Penelitian lain, yaitu D'Sauza dan Rodrigues
(2013) pada hutan mangrove di Goa India Barat, ditemukan genus Glomus, Acaulospora, Scutellospora, Gigaspora dan Entrophospora, yang mana genus Glomus merupakan genus yang dominan.

\section{Kolonisasi fungi mikoriza arbuskula (FMA)}

Pengamatan pada sampel akar 3 jenis tanaman mangrove menunjukkan adanya kolonisasi FMA pada akar. Infeksi akar dapat diketahui dengan adanya hifa, miselia, vesikula atau abuskula. Tingkat persentasi infeksi akar meliputi sangat rendah, rendah, sedang, tinggi, dan sangat tinggi. Hasil perhitungan infeksi akar dapat dilihat pada Tabel 3.

Tabel 3. Persentase Akar Terinfeksi FMA pada Sampel Tanaman Mangrove (A. marina, B. cylindrica, R. stylosa) (Percentage of Infected Root of AMF in Mangrove Samples A. marina, B. cylindrica, R. stylosa).

\begin{tabular}{ccc}
\hline Jenis tumbuhan & Persentase infeksi akar & Keterangan \\
\hline Avicennia marina & $20 \%-32,5 \%$ & Rendah - Sedang \\
Bruguiera cylindrical & $17,5 \%-27,5 \%$ & Rendah - Sedang \\
Rhizophora stylosa & $15 \%-37,5 \%$ & Rendah - Sedang \\
\hline
\end{tabular}

Pengukuran kondisi lingkungan tanaman mangrove di Desa Pasir Kecamatan Mempawah Hilir Kabupaten Mempawah didapatkan rata-rata suhu tanah $28,5^{\circ} \mathrm{C}$, suhu udara $29,8^{\circ} \mathrm{C}$, kelembapan udara 60,8\%, pH tanah 6,2, dan salinitas tanah 4,81 ppt. Kondisi lingkungan ini diduga mempengaruhi keberadaan mikoriza genus Glomus dan besarnya infeksi akar yang terjadi pada 9 sampel tanaman mangrove (A. marina, $B$. cylindrica, $R$. stylosa). Keberadaan dan perkembangan FMA ditunjukkan dengan nilai persentase akar yang terinfeksi mikoriza (Tabel 3), persentase infeksi akar tanaman mangrove jenis Bruguiera cylindrica terinfeksi FMA sangat rendah dibandingkan dengan tanaman Avicennia marina, sedangkan tanaman Rhizophora stylosa mendapatkan persentase infeksi sangat tinggi apabila dibandingkan dengan tanaman A. marina dan B. cylindrica. Infeksi FMA pada tanaman mangrove ini berkaitan dengan keadaan lingkungan tempat tumbuh tumbuhan mangrove, pada saat pengambilan sampel tanaman $A$. marina dan $B$. cylindrica keadaan tanahnya berlumpur, tergenang oleh air laut, dan akar lateral lebih sedikit ditemukan, begitu juga dengan tingkat 
salinitas tanah yang tinggi dengan rerata salinitas tanaman $A$. marina dan $B$. cylindrica $2,78-8,02$ ppt. Keadaan lingkungan tanaman $R$. stylosa saat pengambilan beberapa sampel tidak terlalu berlumpur, tingkat persentase pasirnya lebih tinggi sebesar 19,15 - 26,09\%, rerata salinitas tanaman antara 2,82-4, 75 ppt dan ditemukan lebih banyak akar lateral dibandingkan dengan tanaman $A$. marina dan $B$. cylindrica. Rerata dari keseluruhan infeksi akar pada tanaman mangrove A. marina, B. cylindrica dan $R$. stylosa di Desa Pasir Kecamatan Mempawah Hilir Kabupaten Mempawah termasuk kedalam tingkat klasifikasi kelas rendah-sedang, dikarenakan FMA belum dimanfaatkan sebagai sumber inokulum dengan cara menginfeksikan FMA dalam penanaman persemaian tanaman mangrove. Schenk dan Schroder (1974) menyatakan bahwa suhu terbaik untuk perkembangan arbuskula yakni pada suhu $30^{\circ} \mathrm{C}$, tetapi untuk kolonisasi miselia yang terbaik adalah pada suhu $28^{\circ} \mathrm{C}-35^{\circ} \mathrm{C}$. Pengukuran suhu yang didapat berkisar $29^{\circ} \mathrm{C}-31^{\circ} \mathrm{C}$ menunjukkan di Desa Pasir Kecamatan Mempawah Hilir Kabupaten Mempawah tanaman jenis A. marina, $B$. cylindrica dan $R$. stylosa masih dalam suhu perkembangan FMA dan untuk kolonisasi miselia pada akar tanaman.

Pembentukan FMA setiap jenis mempunyai kisaran $\mathrm{pH}$ optimum yang berbeda-beda serta untuk kondisi lingkungannya pun berbeda pula, nilai $\mathrm{pH}$ optimum untuk proses perkecambahan spora tidak bergantung pada spesies dari FMA, tetapi juga kandungan nutrient yang tersedia di dalam tanah (Miska 2015).
Jenis spora yang memiliki kisaran $\mathrm{pH}$ yang cukup luas untuk perkembangannya berkisar 3.8 sampai 8.0, yaitu Acaulospora scrobiculata, A. morrawi, A. spinosa, Glomus agregatum, G. versiforme, dan Scuttelospora pellucida (Sieverding 1991). Nilai $\mathrm{pH}$ tanah yang telah di ukur di Desa Pasir Kecamatan Mempawah Hilir Kabupaten Mempawah pada tegakkan jenis A. marina, B. cylindrica dan $R$. stylosa didapatkan $\mathrm{pH}$ tanah antara 6,06,7 dimana pada lingkungan ini pembentukkan dan perkecambahan spora FMA dimungkinkan terjadi. Menurut Siradz dkk. (2007) Lokasi didominasi oleh fraksi lempung berdebu merupakan tanah yang baik bagi perkembangan Glomus begitu juga dengan tanah mangrove yang bercirikan tanah berlumpur dan cenderung liat hanya Glomus sp. yang dominan hidup, sedangkan tanah yang berpasir genus Acaulospora dan Gigaspora ditemukan dalam jumlah yang tinggi. Jenis tanah pada tanaman mangrove di Desa Pasir Kecamatan Mempawah Hilir Kabupaten Mempawah berupa tanah berlumpur dengan rerata tekstur tanah dari 9 sampel tanaman mangrove yaitu pasir $10,5 \%$, debu $50,41 \%$ dan liat 39,08\%, ditemukan 7 tipe Glomus spp. Hal ini menunjukkan spora genus Glomus dapat menyesuaikan diri pada lingkungan dan menunjukkan toleransi yang tinggi dan adaptasi yang berbeda.

Keberadaan FMA pada rizosfer dapat dimanfaatkan sebagai sumber inokulum dalam pengembangan dan pemanfaatan FMA sebagai agens hayati dalam penanaman di persemaian untuk rehabilitasi hutan mangrove di Desa Pasir 
Kecamatan Mempawah Hilir Kabupaten Mempawah. Salah satu masalah yang akan terjadi dalam program rehabilitasi adalah tanaman yang ditanam banyak yang mengalami kematian, apabila tanaman tersebut mampu hidup, biasanya pertumbuhannya buruk (Setiadi 1995). Oleh karena itu FMA sangat diperlukan untuk meningkatkan keberhasilan program rehabilitasi menggunaan mikoriza yang dikombinasikan dengan pupuk kimia dengan dosis yang sangat rendah. Secara ekologis, FMA adalah agens hayati yang ramah lingkungan dan tidak menyebabkan pencemaran lingkungan seperti pupuk kimia. Efisiensi penggunaan pupuk kimia dapat dikurangi hingga lebih dari 50\% di tingkat persemaian (Santoso 2007). Menurut Anas dan Tampubolon (2004), akar tanaman inang yang banyak dengan derajat infeksi akar oleh FMA yang tinggi merupakan indikator sumber inokulum FMA yang baik. Cara yang paling umum dipakai dalam memproduksi inokulasi FMA adalah dengan metode kultur pot (pot culture) yaitu FMA yang telah diketahui keefektifannya diinokulasikan pada tanaman inang tertentu pada medium padat yang steril (Simanungkalit 2004). FMA pada rizosfer tanaman mangrove di Desa Pasir Kecamatan Mempawah Hilir Kabupaten Mempawah dapat dikembangbiakkan dengan cara inokulum spora dan melakukan uji efektivitas untuk mendukung rehabilitasi hutan mangrove supaya mendapatkan hasil inokulum yang berkualitas baik. Pada penelitian Setiadi (2000) dalam rangka reklamasi lahan kritis bekas penambangan nikel, teknik ini telah dicoba dengan hasil memuaskan pada semai sengon, acasia dan bonu di pertambangan nikel. Penelitian Janse (1897) juga menyatakan tentang peranan mikoriza pada jenis-jenis pohon hutan yang ada di Cibodas, Gunung Pangrango, Jawa Barat. Temuannya mengindikasikan, mikoriza berperan dalam rantai makanan di rizosfer akar dan memacu pertumbuhan hampir semua jenis pohon dihutan tropika Indonesia.

\section{Kesimpulan}

1. Hasil penelitian membuktikan bahwa adanya asosiasi fungi mikoriza arbuskula pada tanaman mangrove pada 9 sampel ditemukan infeksi spora pada akar tanaman mangrove. Jumlah spora tertinggi ditemukan dirizosfer $A$. marina dan terendah di rizosfer $B$. cylindrica. Berdasarkan hasil karakteristik spora ditemukan 7 tipe Glomus spp.

2. Berdasarkan rata-rata persentase infeksi FMA pada akar tanaman mangrove jenis Avicennia marina (Forssk.)Vierh, Bruguiera cylindrica (L.) Blume, dan Rhizophora stylosa Griff termasuk dalam klasifikasi kelas rendah-sedang.

3. FMA dapat dijadikan sebagai agens hayati dalam penanaman di persemaian untuk rehabilitasi hutan mangrove di desa Pasir kecamatan Mempawah Hilir kabupaten Mempawah.

\section{Saran}

1. Setelah mengetahui adanya asosiasi FMA pada hutan mangrove di desa Pasir kecamatan Mempawah Hilir kabupaten Mempawah yang telah rusak pasca abrasi pantai, perlu dilakukan rehabilitasi hutan mangrove dengan memanfaatkan mikoriza 
sebagai agens hayati, karena pentingnya peran FMA dalam membantu pertumbuhan tanaman, terutama dalam penyerapan unsur fosfor.

2. Perlu dilakukan penelitian lanjutan untuk mengetahui efektivitas simbiosis yang terjadi dan uji tingkat ketergantungan tanaman mangrove ( $A$. marina, $B$. cylindrica, $R$. stylosa) terhadap FMA, serta penelitian perkembangbiakan inokulum FMA sebagai sarana penyediaan inokulum dalam skala besar untuk diaplikasikan pada bibit tanaman mangrove.

\section{DAFTAR PUSTAKA}

Anas I. 1997. Bioteknologi Tanah. Laboratorium Biologi Tanah. Jurusan. Tanah. Fakultas Pertanian. Institut Pertanian Bogor. Bogor.

Baon JB.1998. Peranan Mikoriza VA Pada Kopi dan Kakao. Makalah disampaikan dalam workshop Aplikasi Cendawan Mikoriza Arbuskula pada Pertanian, Perkebunan dan Kehutanan. Oktober 1998. Bogor.

Brundrett M, Boucher N, Dell NB, Gove T, Malajezuk N. 1996. Working with Mycorrhizas in Forestry and Agliculture. Australia Centre for Internasional Agricultural Researche (ACIAR). Canberra.

Delvian. 2003. Keanekaragaman Fungi Mikoriza Arbuskula di Hutan Pantai dan Potensi Pemanfaatnya. Medan. http:library.USU.ac.id. tanggal akses 16 maret 2016.

Delvian. 2010. Keberadaan Cendawan Mikoriza Arbuskula di Hutan Pantai Berdasarkan Gradien Salinitas. Jurnal Ilmu Dasar, 11 (2): 133-142.

D’Souza J, Rodrigues BF. 2013. Biodiversity of Arbuscular Mycorizal (AM) fungi in mangrove of Goa in West India. Jur of Forestry Research, 24 (3): 515-523.

Galii U, Meier M, Brunold C. 1993. Effect of Cadmium on Nonmycorrhizal and Mycorrhizal Fungus (Laccasaria laccata Scop.Ex.Fr): Sulphate Reduction, Thiols and Distribution of the Heavy Metal. New Phytol, Vol. 125:837-843.

Gustian, Burhanuddin, Herawatiningsih R. 2015. Asosiasi Fungi Mikoriza Arbuskula Pada Avicennia spp. Jurnal Hutan Lestari, Vol. 3 (3) : 441-442.

Janse JM. 1897. Les Endophytes Radicaux de Quelques Plantes Javanaises. Annal. Jardin Bot. Buitenzorg 14 : 53-201.

Kathiresan K, Bingham BL. 2001. Biology of Mangroves and Mangrove Ecosystems. Centre of Advanced Study in Marine Biology, Annamalai University, Parangipettai, India.

Khairuddin B. 2014. Luasan Hutan Mangrove di Kabupaten Mempawah. Institut Pertanian Bogor. Bogor.

Miska MEE. 2015. Respon Pertumbuhan Bibit Aren (Arenga pinnata (Wurmb) Merr.) Terhadap Inokulasi Fungi Mikoriza Arbuskula Indigenous. IPB. Bogor.

Noor YR, Khazali M, Suryadiputra INN. 2006. Panduan Pengenalan Mangrove di Indonesia. Wetlands Internasiaonal Indonesia Programme. PHKA/WI-IP, Bogor.

Rini MV, Arif MAS, Lugito, 2015. Kombinasi Vermikulit dan Pasir Sebagai Media Untuk Memroduksi Fungi Mikoriza Arbuskula Pada Tanaman Inang Jagung (Zea mays L.) dan Kudzu (Pueraria javanica). Jurusan Agroteknologi, Fakultas 
Pertanian, Universitas Lampung. Lampung.

Ruiz-Lozano JM, Azcon R. 2000. Symbiotic efficiency dan infectivity of an autochthonous arbuscular mycorrhyzal Glomus sp. From saline and Glomus deserticola under salinity. Spain.

Saidi AB, Budi SW, Kusmana C. 2007. Status cendawan mikoriza arbuskula hutan pantai dan hutan mangrove pasca tsunami (Studi Kasus di Provinsi Nanggroe Aceh Darussalam dan Pulau Nias). Forum Pascasarjana, Vol. 30 No. 1 Januari 2007:13-25.

Santoso E, Turjaman M, Irianto RSB. 2007. Aplikasi mikoriza untuk meningkatkan kegiatan rehabilitasi hutan dan lahan terdegradasi. Prosiding Ekspose Hasil-Hasil Penelitian, 2007.

Schenck NC, Perez Y. 1990. Manual for the identification of VA mycorrhizal (VAM) fungi. Univ. of Florida Press, Florida, USA.

Schroder VN. 1974. Temperature response of endogone micorrhiza on soybean roots. Mycologia.Hlm 66:71.

Setiadi Y. 1989. Pemanfaatan Mikroorganisme dalam Kehutanan. PAU Bioteknologi. Institut Pertanian Bogor. Lembaga Sumber DayaInformasi. Institut Pertanian Bogor, Bogor.

Setiadi Y. 1992. Petunjuk Laboratorium Mikrobiologi Tanah Hutan. Pusat Antar Universitas Bioteknologi Kehutanan. Direktorat Perguruan Tinggi Swasta. Jakarta.

Setiadi Y. 1995. The Practical Application of Arbuscular Mycorrizhae Fungi for Reforestation in Indonesia Thesis. Kent: Research School of Biosciences, University of Kent.
Setiadi Y. 2000. Status Penelitian dan Pemanfaatan Cendawan Mikoriza Arbuskula dan Rhizobium untuk Merehabilitasi Lahan Terdegradasi. Prosiding Seminar Nasional Mikoriza. Asosiasi Mikoriza Indonesia Pusat Antar Universitas (PAU Bioteknologi IPB. Badan Litbang Kehutanan dan Perkebunan. The Brikish Council (Jakarta). Bogor.

Sieverding E. 1991. Vesicular Arbuscular Mycorrhiza management in tropicalagrosystem. Eschborne. Deutsche Gesselschaft fur Technische Zusammenarbeit. Colombia.

Simanungkalit RDM. 2004. Teknologi Cendawan Mikoriza Arbuskular: Produksi Inokulan dan Pengawasan Mutunya. Prosiding Seminar Mikoriza Teknologi dan Pemanfaatan Inokulan EndoEktomikoriza untuk Pertanian, Perkebunan. Universitas Padjadjaran. Bandung.

Siradz SA, Kabirun S. 2007. Pengembangan Lahan Marginal Pesisir Pantai dengan Bioteknologi Masukan Rendah. Jurnal Ilmu Tanah dan Lingkungan. Jurusan Tanah, Fakultas Pertanian UGM. 7 : 83-92. 